\title{
Ethics education in public health: where are we now and where are we going?
}

\author{
Victoria Doudenkova ${ }^{1}$ (D) \\ Jean-Christophe Bélisle-Pipon ${ }^{1,2}$. \\ Louise Ringuette $^{1}$ - Vardit Ravitsky ${ }^{1,2}$. \\ Bryn Williams-Jones ${ }^{1,2}$
}

Published online: 23 March 2017

(C) Springer International Publishing AG 2017

\begin{abstract}
Over the last decade there has been a noticeable increase in attention, on the part of public health scholars and professionals, to the important ethical challenges that arise in the context of public health policy, practice and research. This has arguably been a driver for the development of public health ethics (PHE) as both a specialized field of study in bioethics and a subject for professional education. But how is PHE taught in public health programs and schools? Are current educational approaches sufficient to provide future professionals with the necessary tools to address the diverse ethical challenges they will encounter? In this article, we examine the international public health and bioethics literatures regarding PHE education in public health programs and schools. Specifically, we 1) summarize the results from studies that describe PHE education in the United States, Europe, Canada and in some developing countries, 2) explore current attitudes and educational approaches toward ethics curricula in public health, and 3) identify and discuss reported barriers to PHE education. We conclude with some general recommendations and a research agenda to guide future work on implementing PHE into different public health programs.
\end{abstract}

Keywords Curriculum $\cdot$ Education $\cdot$ Public health programs $\cdot$ Public health ethics

Victoria Doudenkova

victoria.doudenkova@umontreal.ca

1 Bioethics Program, Department of Social and Preventive Medicine, Université de Montréal, Montréal, Québec, Canada

2 Institut de recherche en santé publique de l'Université de Montréal (IRSPUM), Montréal, Québec, Canada 


\section{Introduction}

In the current age of public health challenges faced nationally and globally, to have an ethically untrained public health force is arguably, immoral and unethical. (Kanekar and Bitto 2012: 5)

Recognition of the important ethical challenges faced by public health professionals is arguably one of the major drivers, in the last decade, for the development of public health ethics (PHE) as both a specialized field of study in bioethics and as a subject for improved professional education (Aceijas et al. 2012; Kanekar and Bitto 2012). In contrast to much of North American bioethics - which has tended to focus on issues related to clinical ethics and individual autonomy - PHE is more in line with public health practice and so characterized by a population focus and attention to issues of public policy. The issues explored in PHE are thus most often those that are of practical concern for public health professionals, researchers and policy makers (e.g., issues of social benefit or resource allocation).

In the context of PHE education, the aim is to provide a foundation for critical reflection and ethical judgment on the part of public health professionals, students and researchers (Callahan and Jennings 2002), so that they can be better equipped to deal with the various challenges and dilemmas they will face in their practice (Pati et al. 2014). Callahan and Jennings (2002) delineate four categories of contexts in which ethical issues can occur in public health: 1) health promotion and disease prevention, 2) risk reduction, 3) epidemiological and other public health research, and 4) structural and socioeconomic disparities. Such ethical issues can include, for example, conflicts of interests, scientific uncertainty and necessity for action, but also balancing the needs of communities with the protection of individual liberties, or the tension between the mission of public health and pressures of financial constraint and political expediency. Another important issue in public health is the prioritization of problems to address in a context of limited resources, which necessitates compromises in the weighing of harms and benefits (Carter et al. 2012). Despite the absence of consensus or an established definition regarding the scope of PHE (Klugman 2008), its emergence as a specialized field of study provides a space for discussion of specific challenges in public health policy and practice. As noted by Callahan and Jennings (2002: 170): "If ethics is understood to be a search for those values, virtues and principles necessary for people to live together in peace, mutual respect, and justice, then there are few issues in public health that do not admit of an ethical perspective."

Public health is multi-professional, interdisciplinary, and context-sensitive. Students and practitioners come from a diversity of professional backgrounds and academic disciplines, and thus must learn to identify and reconcile the particularities and differences of their various disciplinary cultures (e.g., professional responsibilities, publication practices/norms) and between different national and regional health systems, as these relate to public health interventions and research. In this complex context, trainees and professionals may be unsure where to turn for guidance and thus be ill-equipped to negotiate divergent obligations arising from different ethical perspectives (e.g., patientcentred focus on autonomy and choice versus community-centred need to maintain herd immunity via mandatory vaccination) or may not know how to address sensitive issues in research collaborations (e.g., norms of authorship in global health research). 
Ethics education is arguably a cornerstone of health professional training, practice, and research. Training in PHE that is adapted to their particular professional or research contexts can enable students to understand the ethical dimensions of their work, shape their identities and objectives as professionals and/or as researchers, and ensure that they are equipped to recognize and address the numerous ethical challenges that arise in various practice and work environments. Such training fosters standards of professionalism, personal and scientific integrity, and the championing of core values and principles. It can also encourage future professionals to be conscious of "the bigger picture" in relation to the specific decisions they will make in practice (Klugman 2008) and to be transparent about their promotion of public interests, thus enhancing public trust in the public health enterprise.

Given the growing interest in integrating PHE into public health training programs due to recognition by professionals and academic programs, and requirements of accreditation bodies (Lee et al. 2016) - it is particularly important to understand the state of PHE education. To what extent is PHE included (or not) in public health programs? What are the existing attitudes and educational approaches toward ethics curricula in public health? And what are the barriers to an effective integration of ethics in public health education? To help answer these questions, we conducted a review of the international public health and bioethics literatures (in English and French), using three electronic databases (Medline, Embase and Google Scholar), ${ }^{1}$ with particular attention to studies dealing with PHE education in public health programs and schools. ${ }^{2}$ As this paper seeks to describe the state of current discussions about PHE education in the scientific literature, we refer only to a few resources in the grey literature to help contextualize what emerged from the relevant selected papers. Our presentation thus focuses on 1) providing a summary of the literature regarding PHE education in the United States, Europe, Canada and in the developing world (India), 2) exploring attitudes and approaches to the inclusion of ethics in public health curricula, and 3) discussing reported barriers to effective PHE education. We conclude with some general recommendations to help address the existing gaps in research, which could be helpful in guiding future work to support a better implementation of PHE education in public health programs.

\section{International experiences with public health ethics education}

Ethics in now largely recognized as an important and even crucial part of the education of public health professionals and researchers (Kanekar and Bitto 2012). However, relatively little data or recommendations exist that specifically address ethics education in public health programs or schools, worldwide. Most of the existing literature is from the United States and, to a lesser extent, from Europe. These regions place significant value on ethics in public health curricula. In this section we summarize the information

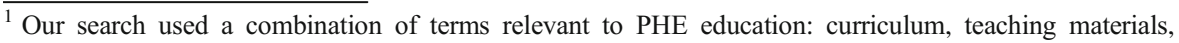
educational models, education, training, teaching, capacity building, competence, ethics, public health ethics, bioethics, public health, population health.

2 'Public health programs' are considered broadly to include: biostatistics, environmental health, epidemiology, global health, health policy and management, social and behavioral science, health promotion and prevention, and workplace and occupational health (Verweij and Dawson 2007).
} 
gathered from the main articles published about the state of PHE education in the United States, Europe, Canada and India (based on a single article).

\section{United States}

The first courses on ethics and public health became part of public health curricula in the 1970s, at the time bioethics was emerging as a new field of study, but remained relatively rare until the mid-1990s (Callahan and Jennings 2002). PHE emerged in the United States in the 1990s as a new field or specialization of bioethics, and the US has continued to play a leading role in both PHE research and education. It is thus understandable that the majority of the literature is American (Aceijas et al. 2012). Interest in PHE is not new, but it took some time to emerge as an area of study because of the dominant focus in American bioethics on individual or clinical issues (Thomas 2008).

In 1974, Bluestone (1976) sent letters to 19 US and Canadian schools of public health to survey the state of ethics education in public health programs. Although the majority of schools did not specifically offer ethics education at the time, the subject was considered to be sufficiently covered in other courses. For example, it was believed that students' questions would raise ethical dimensions of an issue and that no further planning was needed for such instruction. Bluestone also found that there was significant skepticism and even outright doubt that ethics could (or should) be taught. In the late 1990's, Coughlin and colleagues conducted the first survey on the state of ethics education in accredited US public health schools (24 schools surveyed between 1996 and 1997) (Coughlin et al. 1999). They published several studies showing differences in approach towards ethics education across public health programs; they also found that even when specific ethics education was not an obligatory part of a program, it was often offered on an elective basis (e.g., seminars, lectures) (Coughlin 1996; Coughlin et al. 1996, 1999; Coughlin and Etheredge 1995). In order to respond to this heterogeneity in ethics education in public health, Coughlin (1996) advocated for the creation of standardized curricula in PHE education.

In the early 2000s, the Association of Schools and Programs of Public Health (ASPPH), the Health Resources and Services Administration (HRSA), and the Hastings Center began a series of consultations which led to the development of a model curricula for PHE education (Jennings et al. 2003). In the 1990s, the Public Health Leadership Society (2002) produced a code of ethics entitled the Principles of the Ethical Practice of Public Health, which was later adopted by the APHA in 2002. (Thomas et al. 2002). Currently,a new APHA Ethics Code Task Force has been struck to examine the 2002 code and propose revisions to address the current challenges facing public health organizations as well as individual scientists and practitioners. The Task Force has engaged public health professionals and organizations in a deliberative process for approval and adoption of the new code (Lee et al. 2016). According to Lee et al. (2016), the new code should become an important resource for the education and guidance of future public health professionals, because it is more in line with and responds to the actual challenges and ethical dilemmas that these professionals encounter in practice.

The 2002 APHA initiative helped promote the legitimacy and importance of ethical reflection and clarify the values underlying the practice of public health. This work also 
encouraged researchers to identify the ethics skills needed for appropriate public health practice, outlined by Thomas (2004) in Skills for the Ethical Practice of Public Health, a document written for the Public Health Leadership Society. These skills were subsequently used in the development of core competencies for US master's and doctoral programs (Calhoun et al. 2008, 2012), explaining why ethics appears not only in the "professionalism" competency but also transversally through other competencies.

Despite advances made in the US over the last decade with regard to integrating ethics into public health education, there is still room for improvement. In 2006, Agee and Gimbel (2009) assessed the legal and ethical preparedness of Master of Public Health (MPH) graduates in 96 public health programs and schools, and found that there had not been an increase in the number of ethics courses since Coughlin's survey (Coughlin et al. 1999). In fact, only $14 \%$ of programs or schools had mandatory PHE courses, while $30 \%$ offered elective courses. Although their methodology differed from Coughlin's, Agee and Gimbel concluded that little had changed during the preceding decade: "the vast majority of accredited public health schools and programs do not require students to complete graduate courses in ethics or law to obtain an MPH degree" (Agee and Gimbel 2009: 1507).

More recently, Lee et al. (2013) assessed the state of PHE education by examining the websites of 46 accredited schools of public health (SPH), comparing required ethical competencies with the actual state of ethics education. According to Lee, about $50 \%$ of schools surveyed had mandatory ethics courses, at least for some of their students. But while "the number of accredited SPH in North America approximately doubled since 1996, the proportion of schools that require ethics courses for all students in 2010-2011 remained stable or decreased slightly compared with the mid-1990s" (2013: 940). A literature review by Kanekar and Bitto (2012) noted that it remained unclear how much ethics education was given in public health programs, and that there was generally "limited curricular and practice-based opportunities for ethics training" (2012: 5). A possible explanation for the difficulty in integrating ethics in US public health programs may come from an anecdote recounted by Klugman (2008), in which the University of Nevada had to remove an existing ethics course from its program in order to comply with the accreditation requirements of the Council on Education for Public Health (CEPH), i.e., to prioritize other course content, because the CEPH did not explicitly require ethics in the public health curricula.

\section{Europe}

In comparison to the US, only scant literature is available regarding the state of ethics education in European public health programs. The first and most informative European study is by Aceijas et al. (2012), who in 2010-2011 surveyed 82 SPH that were members of the Association of Schools of Public Health in the European Region (ASPHER). They found that some ethics content was included in at least one of the programs at nearly all responding schools (95\%), and thus concluded that ethics content in public health education was highly valued in Europe. Ethics courses were given for the most part in the form of core courses (40-50\%) or were taught across modules, whether for bachelor's or master's programs. Elective courses were also offered, representing a smaller part of ethics teaching (about 10\% in master's programs). Nonetheless, Aceijas and colleagues found significant variability in how ethics was 
integrated in public health programs, the frequency of ethics education and the ethical training of educators. They also identified a widely felt need on the part of educators for the development of support material, such as case studies and model curricula (Aceijas et al. 2012).

Aceijas and colleagues' study is the only pan-European examination of PHE education, although other relevant information can be found in national or multinational (up to three countries) studies. In 1998, Kessel (2003) studied PHE education in the United Kingdom and found that in public health postgraduate education, 52\% of public health schools taught ethics (although not necessarily as a mandatory requirement), but the content and nature of teaching was often unsatisfactory (described as patchy and minimal). Two publications in the early 2000s describe European educators' experiences with teaching ethics in master's programs in SPH. The first, from Croatia, presents the implementation of a "Health, human rights and ethics" master's program in 2005 (Have et al. 2005); the second, from Lithuania, recounts a 10-year experience of ethics teaching, noting that in 2007 there was no such content in public health programs in Latvia, while Estonia and Poland had only just begun introducing ethics content (Jakusovaite and Bankauskaite 2007). This latter article mainly discusses ethics education in public health in the transitional context (towards a democracy and marketoriented society) of Lithuania, which had to deal with important social changes. These national studies, while providing a fragmented picture of PHE education in different European countries, point to the fact that in the early 2000s, ethics was still not or was only poorly integrated into public health curricula.

Thus, discussions in Europe about the need for a model curriculum took place about a decade after those in the US. This is not surprising, however, when one recognizes that ethics was first introduced in US public health programs in the 1970s, as compared to the 1980s in Europe (Have et al. 2005). Nevertheless, interest in PHE in Europe has been growing since the early 1990s (Jakusovaite and Bankauskaite 2007), and so from the limited data available, it appears that current requirements for explicit ethics content in public health education are approximately equivalent in Europe and the US.

\section{Canada}

Ethics in public and population health $(\mathrm{PPH})$ in Canada has been receiving some attention over the last few years (Viehbeck et al. 2011), and work has been done at an institutional level to promote ethics in public health practice and research. For example, the Public Health Agency of Canada (PHAC), the National Collaborating Centre for Healthy Public Policy (NCCHPP) and the Institute of Population and Public Health at the Canadian Institutes of Health Research (CIHR-IPPH) have all noted the growing importance of PPH ethics and encourage the broader discussion of ethical challenges arising in public health. Further, the ability to apply ethical reflection to decision making has been identified as a core competency for Canadian public health professionals since at least 2007 (Public Health Agency of Canada 2007).

The context is thus favourable for the development of ethics training initiatives in Canadian public health programs and schools. However, very little is known about the state of ethics education in Canada. Unlike in Europe (Aceijas et al. 2012) or the US (Lee et al. 2013), there have been no systematic analyses of ethics education in Canadian public health programs. (Our research team is currently conducting such a 
survey in partnership with the NCCHPP). Unlike in the US, in Canada there is no common code of ethics for public health professionals (Public Health Leadership Society 2002), there is no nationally recognized model curriculum for PHE education (Jennings et al. 2003), and there are few models of ethics courses or ethics-related resources for continuing education of public health professionals and researchers (Viehbeck et al. 2011).

Despite a lack of direction about what should constitute ethics education in Canadian public health programs and schools, some recent initiatives support the teaching of PHE. Dawson and Upshur (2013) developed a model curriculum for PHE that was adapted to the Canadian context and organized in six thematic modules aligned to key domains of public health: health protection, health surveillance, disease and injury prevention, population health assessment, health promotion, and disaster response. The model curriculum was developed to help professionals integrate PHE in public health practice, and to support students by providing a basis for the creation of educational programs in PHE. In addition, PHE case studies were published (Joint Center for Bioethics 2013) to provide resources to support debate and discussion of dilemmas arising in public health practice and education.

\section{India}

There is little information accessible or published in English (or French) about the teaching of ethics in public health programs in developing countries. We identified only one study, conducted in India (Pati et al. 2014), and its authors found no standardization of curriculum nor any consensus about ethics education in public health. Concerning MPH programs offered by 31 institutions in India, only 11 had a dedicated module for ethics (elective and compulsory). In the Diploma in Public Health, with some exceptions, ethical training was not included, as was also the case for postgraduate programs in community medicine (Pati et al. 2014). Even if specific topics were covered in independent ethics courses (in workshops, seminars, etc.), there was little ethics education in general nor was there much trust by health professionals in PHE curricula: "In contrast to the USA, where the importance of PHE has been recognised and the area has been strengthened by the model curriculum, initiatives in this sphere are rudimentary in India." (Pati et al. 2014: 9) As it was at the beginning of PHE in the US, it may be that in India trust toward ethics curricula is still limited and thus there is skepticism about the pertinence and the feasibility of such teaching in SPH and programs.

\section{Summary}

The US and Europe have clearly taken the lead in the development of ethics curricula in public health. Yet, while ethics is increasingly recognized as having an important place in public health practice, its integration in public health training programs is less well established. The state of ethics education varies widely, whether within a single country or between countries. In addition, the influence and leadership of the US is notable, and not surprising given the origins of PHE. The US thus serves as a reference for other countries, although American content would need to be adapted to different national and socio-cultural contexts. It is also worth noting that, regardless of the country, the development of PHE education seems to follow a similar pattern (i.e., from distrust and 
resistance, to acceptance and integration of PHE content in training programs). Collaboration between countries could thus be an important facilitator for effective integration of ethics into $\mathrm{PH}$ programs, by sharing experiences and so anticipating possible difficulties. Ethics education in public health also still lacks clear direction, both with regard to quantity (how many hours or courses are offered) and content (what approaches are used and what issues are covered). Although the creation of a model US curriculum has given a direction to PHE training in that country (and elsewhere), the US example shows that addressing the issue from a perspective of standardization is insufficient, insofar as it has not resolved the difficulties and challenges that still exist today in the implementation of such training (see section below, on Barriers).

\section{Exploring attitudes and educational approaches towards ethics curricula in public health}

As observed with ethics education (i.e., existence of obligatory or optional ethics courses), little is known about the ethics material used and taught in public health programs. As Aceijas et al. (2012) note, it is important that qualitative research be conducted to determine the content of ethics curricula and the manner in which ethics is taught to public health students. It seems that the significant variability in educational approaches can be explained by the importance of or the support given to ethics in the curricula of different programs or SPH. But the content is also dependent on the goal of such teaching, which is not easily defined when it comes to PHE education. Thomas (2003) describes the potential goal of ethics education as a continuum between theory and practice, contained in a spectrum ranging from the development of theories to the action of making people behave morally. Between the two extremes, Thomas suggests that a more reasonable goal would be "equipping students of public health to operate within the ethics structures of the field. This entails teaching them what the structures and policies are, their importance, and how to function within them. It also entails teaching students how to reason through ethical problems, appealing to various ethical theories when needed." (Thomas 2003: 282).

This vision seems to be shared by American and European public health programs through the way they conceive of ethics education. PHE can be implicit, for example, and found in some of the foundational skills identified by the Public Health Leadership Society (PHLS) (Thomas 2004), such as the ability to identify an ethical issue and to make ethical decisions by weighing the harms and benefits; the skills related to the understanding of basic ethical concepts and determinants of health; or the skills contributing to the maintenance of public trust. In the same vein, Thomas (2004) suggested putting the emphasis mostly on actions rather than on attitudes with the use of verbs such as recognize, identify, consider, define, articulate, collaborate, advocate, understand, apply, present, prepare, discuss, describe, utilize, or create.

There is, nevertheless, some nuance in the motivations for integrating ethics education in public health programs. Some authors see PHE simply as a pragmatic means of problem solving, as a tool to deal with challenging dilemmas; as Coughlin (Coughlin et al. 1999: 770) notes "Curricula in PHE are designed not to improve the moral character of students but rather to provide them with conceptual abilities and decision making skills they will need to deal successfully with ethical issues in their own 
research and practice”. But others see PHE as going beyond problem solving skills or an analysis of the tensions between the needs of individuals and society (Bluestone 1976), arguing that it can operate at both procedural (problem solving) and cognitive levels, and be the basis for integrating systematic reflection and the development of ethical sensitivity (Aceijas et al. 2012; Have et al. 2005). Some authors have even suggested that ethics education enhances the moral character of students (Jakusovaite and Bankauskaite 2007), although others continue to argue that ethics training does not necessarily make students behave morally (Kanekar and Bitto 2012). While this question may not be easily resolved, the continued development and expansion of ethics curricula should encourage consideration of the goals underlying ethics instruction. It may not be possible or even appropriate to establish a unique vision with which to create, test or revise PHE curricula; but this does not diminish the importance of considering those goals in analyses of current training programs or future developments.

\section{The content and educational methods of ethics education}

Different guidelines and frameworks exist to support ethics analyses in public health. These tools are meant to facilitate the achievement of the goals of PHE as well as bridge the gap between theory and public health practice. But since no single ethical framework is likely to address the full diversity and multitude of ethical challenges that arise in public health, and there will be different philosophical foundations for such tools, a diversity of tools is likely inevitable and even desirable. For example, ethical analysis can be guided by different ethical approaches such as professional ethics, advocacy ethics, critical ethics, research ethics or even bioethics more generally (Callahan and Jennings 2002; Lee et al. 2013). Some frameworks ${ }^{3}$ are designed specifically for decision-making by public health professionals involved in program implementation (Kass 2001), while others can be useful to track where and when ethical issues could arise (Childress et al. 2002). More systematic approaches to ethical analysis also exist, such as the framework created by Marckmann et al. (2015), which proposes an evidence-based approach to PHE that is grounded in both a clearly defined ethical foundation and a methodological approach to address PHE issues.

Principle-based approaches represent one of the major tools to support ethical analysis in public health. For example, Upshur's (2002) Principles for the Justification of Public Health Intervention, designed for public health practitioners, discusses the principles of harm, reciprocity, transparency and the principle of least restrictive means. Schröder-Bäck et al.' (2014) principles are specific to public health education and are used by several European universities, such as the École des hautes études en santé publique in France, Maastricht University in the Netherlands, and Bielefeld University in Germany. The framework consists of seven mid-level principles: the four wellknown biomedical ethics principles (beneficence, non-maleficence, respect for autonomy and justice) (Beauchamp and Childress 2012) adapted for the public health context, and three additional principles (health maximization, proportionality and efficiency). The approach was also specifically developed to facilitate the introduction

\footnotetext{
${ }_{3}$ A non-comprehensive, but continuously evolving, list of frameworks can be found at: http://www.ncchpp. ca/708/Repertoire_of_Frameworks.ccnpps
} 
of ethics teaching into crowded public health curricula, requiring only five to eight hours of in-person teaching (Schröder-Bäck et al. 2014).

The principle-based approaches used in PHE tend to include a more expansive list of principles than found in biomedical ethics, as they need to address the complexity of issues raised in the public health context. For example, Kanekar and Bitto (2012) include connectedness, solidarity and communal responsibility as additional principles. This broader scope allows the consideration of principles involved in both individual and collective dimensions that are important to PHE (Dawson and Upshur 2013), but that are not always explicit in biomedical ethics (Klugman 2008).

PHE can also employ other approaches besides principle-based ethics frameworks. For example, ethics education in public health programs can be taught through the use of ethical theories, such as utilitarianism and deontology, or through the use of key themes, such as the allocation of resources in healthcare, disease or injury surveillance and prevention, research ethics, law and ethics, or health and human rights (Dawson and Upshur 2013; Jakusovaite and Bankauskaite 2007; Lee et al. 2013). Ethics can also be taught based on practical problems by using, for example, case studies related to different themes. Tulchinsky et al. (2015) highlight the advantages of using case studies in ethics training, noting that their use makes it easier to contextualize (make learning realistic and practical), and foster discussion between $\mathrm{PH}$ professionals and citizens in order to better anchor the PH practice with real-world needs.

Further, programs can adopt 'bottom-up' (starting with cases or specific situations) or 'top-down' (starting from theories or overarching principles) approaches, or a mix of the two, to enhance students' comprehension of the multifaceted and multilevel nature of the ethical approaches they can use to address the issues they could face in their practice. In some programs, as in Lithuania, the starting point for ethics education is ethical theory, with a top-down approach, where practical issues anchor and illustrate the theoretical framework (Jakusovaite and Bankauskaite 2007). Alternatively, some suggest offering "a program that deals specifically and exclusively with the unique challenges presented by public health.” (Klugman 2008: 61) Modell and Citrin (2002) provide a detailed example of how an ethics course dealing with specific issues can be taught. This course - which is focused on public health genetics - is structured in several segments (background, issues of research and practice, policy tools and perspectives, ethical perspectives and policy development session) and presented in a way that creates a coherent and nuanced narrative; this permits a rich overview of specific issues in genetics as well as the main ethical theories and principles pertinent to public health. Others suggest a course design that meets the needs of students as a better starting point for understanding and incorporating ethical reflection and decisionmaking into practice and research (Jakusovaite and Bankauskaite 2007; Modell and Citrin 2002).

A wide variety of methods of ethics instruction exist, such as seminars, lectures, personal readings, formal courses, case-based discussion, small-group discussions, role-play simulations and creative self-activity (Have et al. 2005; Jakusovaite and Bankauskaite 2007; Slomka and Quill 2008). Using a diversity of methodologies and pedagogical approaches is considered beneficial, as it contributes to the richness of ethics curricula in public health. For instance, studies of masters programs in countries in transitional contexts (Have et al. 2005; Jakusovaite and Bankauskaite 2007) emphasized the importance of adapting teaching methodologies to the particular context of the 
country. This is justified by the fact that future decisions made by students will have to be anchored in the needs and perceptions of the culture of a specific community. As Coughlin (2009) notes, curricula have to be flexible enough to meet the needs and particularities of different public health programs, and they should leave room for innovation and creativity (Coughlin et al. 1999). Thus, PHE education should ideally be adapted to students' contexts and needs, as well as to local social objectives. Regardless of the method used, actively involving students seems to be one of the most important components of PHE training (Pati et al. 2014). To this one can add the need to actively involve PH educators and SPH in making PHE broadly relevant to students, and an important part of their training. According to Tulchinsky et al. (2015), since $\mathrm{PH}$ is intrinsically interdisciplinary, it is important that the content of training courses also be accessible for and shared with not only graduate students in $\mathrm{PH}$, but also across the many other PH professions (such as medicine, nursing, social work, economics, health management and politics) which have an important role to play in fostering public health.

\section{Barriers to public health ethics education}

Our analysis of the literature shows that promoting and creating a space for PHE education in public health programs and schools is challenging, for reasons that go beyond the mere fact that PHE is a relatively recent and emerging field. The fact is that teaching ethics is also dependent on the goal ones aims to meet, thus it forces consideration of an array of different educational approaches. But implementing ethics education in public health programs and SPH meets with some notable barriers.

While the variability of ethics training, content and methodology is important and can be seen as useful, the absence of harmonization is also a significant barrier. Considering that there are important moral imperatives underlying public health practice that are shared and regarding which all practitioners should be ethically trained, the lack of harmonization in PHE education entails possible variability in standards of practice that can be detrimental to the field as a whole. Harmonization does not solve all problems, but like codes of ethics, can serve as a "moral compass" for guiding the improvement of practices (Callahan and Jennings 2002). Another barrier stems from the disciplinary gap between prevalent approaches in the field of public health and those of ethics, as is well described by Callahan and Jennings (2002: 174):

The teaching of ethics is controversial primarily because the dominant ethos of most professions is empiricist, quantitative, and oriented toward precise, definitive solutions to discrete problems. This often does not comport well with the intellectual characteristics of ethical analysis, which focus on the multifaceted nature of problems - the difficulty in finding definitive solutions to problems that take complex forms as analogies, narratives, or dilemmas - and on the qualitative and interpretative character of moral judgment in contrast to the quantitative knowledge that carries legitimacy in most professional fields.

It is thus understandable that when ethics teaching is not "labelled" as such - and instead integrated into teaching of 'professionalism' or 'leadership', for example - it 
may be better accepted by students (Jakusovaite and Bankauskaite 2007; Thomas 2003). This leads to the question of how ethics teaching and a commitment to ethical behaviour are perceived and valued by the communities involved, whether in universities or practice settings. According to Callahan and Jennings (2002), this is a sign of the difficulty in bringing to maturity an interest in ethics; even if the interest is there, it does not always results in concrete changes. Thus a flexible and progressive attitude, as Kessel (2003) suggests, could promote a better acceptance of ethics teaching in both academic and professional contexts and contribute to more ethics-friendly professional and institutional cultures. A way to reduce this barrier can be seen in the proposition by Lee and Royo-Bordonada (2015) to use a strategy that contributes to an early integration of ethics education in public health practice, research and policy. In so doing, they argue that the perception that "ethics is a tool to restrict, stop, or criticize public health activities or personnel" (Lee and Royo-Bordonada 2015: 3) can be transcended.

Offering ethics training in the context of limited resources and a busy curricula that focuses on technical skills is another important barrier (Callahan and Jennings 2002; Coughlin 2009; Kessel 2003; Schröder-Bäck et al. 2014). Limited resources can include lack of teaching materials for PHE (or lack of awareness of existing materials), lack of financial or sustained institutional support for the development of ethics training, and a lack of adequately trained educators. Indeed, there are only a few dedicated diplomas in PHE where current graduates could be trained to become tomorrow's educators. Further, there is still no consensus on what should be the level of training of PHE educators or their specialty (Aceijas et al. 2012; Jakusovaite and Bankauskaite 2007; Kessel 2003). For example, PHE could be taught by a public health professional with some ethics training and/or by a bioethicist with complementary public health training (Kanekar and Bitto 2012).

Another barrier identified in the literature is the strong relationship between public health and the political sphere. As ethics often involves the use of critical approaches in the questioning of a particular social order or institution (Carter et al. 2012), it is easy to imagine that ethical questioning of the strengths and weaknesses of a particular public health intervention or policy might not always be welcome. For example, "What are you or I as professionals to do about the aggressive, profit-motivated actions of governments and private enterprise that are damaging human health, either directly (tobacco) or indirectly (pollution and over-nutrition)?" (Leeder 2004: 436) This raises a fundamental question about the role and limits of public health professionals as advocates for public health, and thus reinforces the place for ethics training in promoting the legitimacy of asking such questions.

An understanding of the barriers facing PHE education can, we suggest, enhance our ability to better integrate ethics into public health, whether in SPH or in practice. Parallel to the creation of guidelines, curricula or recommendations, it is important to strive to understand and address the broader context in which PHE is being implemented.

\section{Conclusion}

As a first step in understanding the state of public health ethics education internationally, this snapshot of the key articles available (in English or French) in the scientific 
literature provides an important update to the state of PHE education in the US, Canada and Europe. Through these articles, we documented and discussed some of the existing attitudes and educational approaches toward ethics curricula in public health, as well as barriers to PHE education.

There is not an abundant literature, either in public health or in bioethics, about PHE education. The subject is relatively new in public health, but interest in ethics education is evident and whether it is in Europe or the US, the importance of having ethics content in public health education is increasingly recognized. The relative paucity of studies, however, makes it clear that more research is needed in order to evaluate the state of ethics education in public health, and to provide comparative analyses between countries to identify lessons learned. For instance, only one pan-European study has been conducted to date and there is a lack of detailed national studies, apart from the US.

How much time is dedicated to ethics (e.g., a few hours in different modules, or dedicated courses)? What and how is ethics taught, and by whom? And what are the specific barriers to the development of ethics curricula? Our review of the scientific literature provides some useful insights, but both quantitative and qualitative studies are needed to more fully answer these questions. Quantitative studies could help to document more precisely the extent of the integration of ethics education in public health programs (how much ethics is taught, where, and by whom?) ideally using a standardized methodology, since the available studies use various methods and so are difficult to compare. Qualitative studies could provide a deeper understanding of the modalities and the content of ethics education (what is taught, and how?), the challenges to its implementation in the university community, and the satisfaction and challenges of educators, administrators and students, as well as practice settings (is the ethics content pertinent?). It could also be an effective means of assessing the legitimate variability of ethics instruction in helping to tailor curricula to students' specific fields of public health (i.e., need for different educational approaches and content). PHE education will gain a great deal by considering curricula not only from the point of view of researchers, but also from the feedback of educators and students who have tested particular curricula in different settings. Our paper provides an overview of current discussions in the scientific literature about PHE education; a comprehensive analysis of the grey literature (e.g., reports by government agencies or professional associations) was beyond the scope of our study. Such an analysis is also needed and would be an important second step in understanding the state of ethics education in public health programs and SPH, internationally, and could even be extended to review PHE education in other health professions (e.g., medicine, nursing).

In most countries, there are no data available about the state of PHE education, nor are comprehensive resources available for $\mathrm{PH}$ schools or programs wishing to introduce ethics as part of their curricula. To address this gap, we strongly encourage researchers to conduct studies in a variety of countries and settings. This would also provide resources to help $\mathrm{PH}$ programs and $\mathrm{SPH}$ better implement context-sensitive and specific PHE content into their curricula. A first step might simply be to survey directors and ethics educators of programs/schools of public health to evaluate the state of ethics education (e.g., how much PHE is taught, what is taught, and by whom?). Alongside such quantitative research, it would be important to conduct qualitative research to better understand the contexts, facilitators and barriers to the development of PHE education as well as the effectiveness of different educational 
methods. Indeed, we would argue that what is missing is a comparative analysis of educational methods in PHE instruction, similar to the study by Mulhearn et al. (2016). For a field that "has been slow to meet this educational responsibility" (Tulchinsky et al. 2015: 2), promoting more effective educational methods can be a good way to foster ethics education in PH. These research efforts, conducted internationally, would lay the groundwork for a better understanding of what is needed to constitute appropriate and pertinent public health curricula and address the problem of standardization by ensuring that the curricula are context and setting-specific.

The current state of ethics education in public health programs, internationally, seems to be more the result of incidental or opportunistic developments rather than a deliberate and coherent plan, as evidenced by the paucity of specific recommendations or model curricula and by a lack of harmonization. The only certainty in PHE education, and one that seems to be shared in the bioethics and public health literatures, is that it is important, highly variable in quantity and content, and that there is still significant room for improvement. Nevertheless, the multidisciplinary nature of public health, as well as the demonstrated and sustained interest in ethics training by universities and practice settings are important strengths with which to address the barriers to integrating ethics in public health curricula. Considering the current international public health organizational structure (World Health Organization, countries, states or provincial and regional public health organizations), international and national public health organizations could potentially play an important role in facilitating the sharing of resources and experiences, and even the coordination of international comparisons. Such initiatives could provide important stimulus to the development of an evidencebase for a minimal set of core competencies in public health ethics that are sufficiently general and flexible so that they can be adapted to diverse national contexts and so integrated effectively into the curricula of public health programs and schools.

Acknowledgements We would like to express our special thanks to Olivier Bellefleur and Michael Keeling for revising the final version of this paper.

Funding Funding for this study comes from the Canadian Institutes of Health Research (CIHR) Ethics Office (Grant number: 201306MPE-309,671). Doudenkova is supported by a graduate scholarship from the Bioethics Program and the Faculty of Graduate and Postdoctoral Studies of the Université de Montréal. Bélisle-Pipon is supported by a Ph.D. scholarship from the Fonds de recherche du Québec-Santé (FRQ-S) \& Unité SOUTIEN-SRAP du Québec. Ravitsky's research is funded by CIHR and Genome Canada. WilliamsJones' research is funded by CIHR and the Social Sciences and Humanities Research Council of Canada (SSHRC).

\section{Compliance with ethical standards}

Conflict of interests None to declare.

\section{References}

Aceijas, C., C. Brall, P. Schröder-Bäck, et al. 2012. Teaching ethics in schools of public health in the European region: findings from a screening survey. Public Health Rev 34 Available from: http://www. publichealthreviews.eu/show/p/101. 
Agee, B., and R.W. Gimbel. 2009. Assessing the legal and ethical preparedness of master of public health graduates. Am J Public Health 99 (8): 1505-1509.

Beauchamp, T.L., and J.F. Childress. 2012. Principles of biomedical ethics. 7th ed. Oxford: Oxford University Press.

Bluestone, N.R. 1976. Teaching of ethics in schools of public health. Am J Public Health 66 (5): 478.

Calhoun, J.G., K. Ramiah, E.M. Weist, et al. 2008. Development of a core competency model for the master of public health degree. Am J Public Health 98 (9): 1598-1607.

Calhoun, J.G., J.E. McElligott, E.M. Weist, et al. 2012. Core competencies for doctoral education in public health. Am J Public Health 102 (1): 22-29.

Callahan, D., and B. Jennings. 2002. Ethics and public health: forging a strong relationship. Am J Public Health 92 (2): 169-176.

Carter, S.M., I. Kerridge, P. Sainsbury, et al. 2012. Public health ethics: informing better public health practice. New South Wales Public Health Bulletin 23 (6): 101-106.

Childress, J.F., R.R. Faden, R.D. Gaare, et al. 2002. Public health ethics: mapping the terrain. The Journal of Law, Medicine \& Ethics: A Journal of the American Society of Law, Medicine \& Ethics 30 (2): 170-178.

Coughlin, S.S. 1996. Model curricula in public health ethics. Am J Prev Med 12 (4): 247-251.

Coughlin, SS. 2009. Model Curricula in Public Health Ethics. In: Ethics in Epidemiology and Public Health Practice, American Public Health Association. Available from: http://ajph.aphapublications. org/doi/pdf/10.2105/9780875531939ch08 Accessed 24 October 2014.

Coughlin, S.S., and G.D. Etheredge. 1995. Teaching ethics and epidemiology: initial experiences at two schools of public health. Epidemiol Monitor 16: 5-7.

Coughlin, S.S., G.D. Etheredge, C. Metayer, et al. 1996. Remember Tuskegee: public health student knowledge of the ethical significance of the Tuskegee syphilis study. Am J Prev Med 12 (4): 242-246.

Coughlin, S.S., W.H. Katz, and D.R. Mattison. 1999. Ethics instruction at schools of public health in the United States. Am J Public Health 89 (5): 768-770.

Dawson, A., and R. Upshur. 2013. A model curriculum for public health ethics. In Ethics in public health and health policy, ed. D. Strech, I. Hirschberg, and G. Marckmann, 103-118 . Dordrecht: Springer Netherlands Accessed 9 October 2014.Available from: http://link.springer.com/10.1007/978-94-0076374-6 8

Have, H.T., A. Borovečki, and S. Orešković. 2005. Master Programme 'health, human rights and ethics': a curriculum development experience at Andrija Štampar School of Public Health, medical school, University of Zagreb. Med Health Care Philos 8 (3): 371-376.

Jakusovaite, I., and V. Bankauskaite. 2007. Teaching ethics in a masters program in public health in Lithuania. J Med Ethics 33 (7): 423-427.

Jennings, B., J. Kahn, A. Mastroianni, et al. 2003. Ethics and public health: model curriculum. Washington: Health Resources and Services Administration, Association of Schools of Public Health and Hastings Centre Available from: http:/www.aspph.org/app/uploads/2014/02/EthicsCurriculum.pdf Accessed 15 December 2016.

Joint Center for Bioethics. 2013. Population and public health ethics: cases from research, policy and practice. University of Toronto Accessed 11 May 2015.Available from: http://jcb.utoronto. ca/publications/casebook.shtml

Kanekar, A., and A. Bitto. 2012. Public health ethics related training for public health workforce: an emerging need in the United States. Iranian Journal of Public Health 41 (4): 1-8.

Kass, N.E. 2001. An ethics framework for public health. Am J Public Health 91 (11): 1776-1782.

Kessel, A.S. 2003. Public health ethics: teaching survey and critical review. Soc Sci Med 56 (7): 1439-1445.

Klugman, C. 2008. A tale of two fields: public health ethics. Monash Bioethics Review 27 (1-2): 56-64.

Lee, L.M., and M.Á. Royo-Bordonada. 2015. Continuing the conversation about public health ethics: education for public health professionals in Europe. Public Health Rev 36: 5.

Lee, L.M., B. Wright, and S. Semaan. 2013. Expected ethical competencies of public health professionals and graduate curricula in accredited schools of public health in North America. Am J Public Health 103 (5): 938-942.

Lee, L.M., C.B. Fisher, and B. Jennings. 2016. Revising the American public health Association's public health code of ethics. Am J Public Health 106 (7): 1198-1199.

Leeder, S.R. 2004. Ethics and public health. Intern Med J 34 (7): 435-439.

Marckmann, G., H. Schmidt, N. Sofaer, et al. 2015. Putting public health ethics into practice: a systematic framework. Front Public Health 3 Accessed 15 December 2016.Available from: http://journal.frontiersin. org/article/10.3389/fpubh.2015.00023/abstract

Modell, S.M., and T. Citrin. 2002. Ethics instruction in an issues-oriented course on public health genetics. Health Educ Behav 29 (1): 43-60. 
Mulhearn TJ, Steele LM, Watts LL, et al. (2016) Review of Instructional Approaches in Ethics Education. Science and Engineering Ethics: 1-30. doi:10.1007/s11948-016-9803-0

Pati, S., A. Sharma, and S. Zodpey. 2014. Teaching of public health ethics in India: a mapping exercise. Indian Journal of Medical Ethics 11 (3): 185-190.

Public Health Agency of Canada. 2007. Core competencies for public health in Canada release 10 Ottawa: Public Health Agency of Canada. Available from: http://www.phac-aspc.gc.ca/php-psp/ccph-cesp/about cc-apropos_ce-eng.php.

Public Health Leadership Society. 2002. Principles of the ethical practice of public health. LA: New Orleans Available from: https://www.ncbi.nlm.nih.gov/pmc/articles/PMC1447186.

Schröder-Bäck, P., P. Duncan, W. Sherlaw, et al. 2014. Teaching seven principles for public health ethics: towards a curriculum for a short course on ethics in public health programmes. BMC Medical Ethics 15 (1): 73.

Slomka J, Quill B, des Vignes-Kendrick M, et al. (2008) Professionalism and ethics in the public health curriculum. Public Health Rep 123(Suppl 2): 27-35.

Thomas, J.C. 2003. Teaching ethics in schools of public health. Public Health Reports (1974) 118 (3): 279 286.

Thomas, J.C. 2004. Skills for the ethical practice of public health. Public Health Leadership Society Accessed 22 May 2015.Available from: http://phls.org/CMSuploads/Skills-for-the-Ethical-Practice-of-PublicHealth-68547.pdf

Thomas, J.C. 2008. An agenda for public health ethics. Journal of Public Health Management and Practice 14 (4): 329-331.

Thomas, J.C., M. Sage, J. Dillenberg, et al. 2002. A code of ethics for public health. Am J Public Health 92 (7): 1057-1059.

Tulchinsky, T., B. Jennings, and S. Viehbeck. 2015. Integrating ethics in public health education: the process of developing case studies. Public Health Rev 36: 4.

Upshur, R.E.G. 2002. Principles for the justification of public health intervention. Can J Public Health 93 (2): $101-103$.

Verweij M and Dawson A (2007) The Meaning of 'Public' in 'Public Health'. In: Dawson A and Verweij M (eds), Ethics, Prevention, and Public Health, Clarendon Press.

Viehbeck, S.M., R. Melnychuk, C.W. McDougall, et al. 2011. Population and public health ethics in Canada: a snapshot of current National Initiatives and future issues. Can Jn 102 (6): 410-413. 